\title{
Chapter 11 \\ Mathematical Values Through Personal \\ and Social Values: A Number Activity \\ in a Japanese Kindergarten
}

\author{
Nagisa Nakawa
}

\begin{abstract}
This chapter discusses the possibility of incorporating the framework of mathematical, social, and personal values into a number activity, following the approach shown in Shimada and Baba (Transformation of students' values in the process of solving socially open-ended problems. In: Beswick K, Muir T, Wells J (eds) Proceedings of 39th psychology of mathematics education conference, vol 4. PME, Hobart, Australia, pp. 161-168, 2015). The qualitative analysis showed that kindergarten children regarded equality and fairness as very important among their personal and social values when distributing sweet potatoes to two different kinds of animals in an imaginary restaurant. Further, these social and personal values became a driving force toward mathematical values: children verbally expressed their logical opinions related to different quantities (the size of animals' mouths), an ability closely linked with the beginning of rationality in mathematical values. Therefore, social and personal values can serve as a catalyst for kindergarteners to organically develop mathematical values.
\end{abstract}

Keywords Social values $\cdot$ Personal values $\cdot$ Mathematical values $\cdot$ Mathematical play $\cdot$ Kindergarten mathematics

\subsection{Introduction}

In Japanese public kindergartens, which are pre-schools for children aged three to six, cultivating a foundation for lifelong character-building through play is viewed as crucial (Japanese Ministry of Education, Culture, Sports, Science and Technology [MEXT] 2008, p. 1). Teaching and learning in Japanese public kindergartens are not subject-based, but play-based, connecting to children's daily life to foster their mental and physical development. Therefore, mathematics is not a discrete "subject"; instead, mathematical skills are integrated across the five focal areas to be learned

N. Nakawa $(\bowtie)$

Kanto Gakuin University, 1-50-1, East Mutsuura, Kanazawa Ward, Yokohama,

Kanagawa 236-8501, Japan

e-mail: nagisa@kanto-gakuin.ac.jp

(C) The Author(s) 2019

P. Clarkson et al. (eds.), Values and Valuing in Mathematics Education,

ICME-13 Monographs, https://doi.org/10.1007/978-3-030-16892-6_11 
in the national Course of Study for Kindergarten: health, human relationships, environment, languages, and expression. These are said to be essential for children's cognitive and physical development at pre-primary level (MEXT 2008, 2017b). The ultimate objective of kindergarten in Japan is to establish a foundation for the formation of one's mature personality (MEXT 2017b, p. 3). The author and the research team involved in this developmental project for early mathematics, surmised that teaching mathematics including different values would fit into kindergarten education if it included an element of values education.

This chapter reports on the implementation and results of that kindergarten mathematics project, with a particular focus on different values in a mathematical activity - the Development of the Elementary Mathematics Education Training Program for Preschool Teachers and Parents (the DEMETP). Focusing on mathematics, which deals with children's values as well as their cognitive development in preparation for primary mathematics, the goal of this chapter is to use the perspective of children's social, personal, and mathematical values to examine the quality of learning about numbers through a teaching/learning activity called "sweet potato sharing".

\subsection{DEMETP Project}

The aim of the DEMETP project is to develop a curriculum for mathematics teaching and learning which fits into the current Course of Study for Kindergarten. As Matsuo (2015) has explained, the project broadly focuses on the formation of relationships between teacher and children and on interactions between the children and objects in mathematical activities. The project has three pillars in its curriculum framework. The first is the classification of educational objectives in relation to the cognitive and affective development of children. The second is mathematical content and teaching method. While primary school mathematics in Japan consists of four areas - numbers and calculation, quantity and measurement, geometry, and the relationship between number and quantity - this project broadly covers number and quantity, shapes, number change, and the relationship between numbers and quantity to link kindergarten and primary school mathematics. It is concerned with basic problem-solving and representation considering the developmental stage of young children. The third pillar integrates the five areas to be learned as mentioned in the Course of Study for Kindergarten with basic learning attainment and mathematical literacy. The stages of each activity in this project are as follows: (1) adopting an activity and setting a problem, (2) preparation, (3) organisation of the classroom, and (4) implementation of the activity. So far, the project team has developed nineteen activities in different areas of mathematics and are in the process of examining their effectiveness. 


\subsection{Learning Numbers and Division}

Mathematics is barely discussed in the Course of Study for Kindergarten. As mentioned, mathematics is not a separately-taught subject; however, children are encouraged to learn mathematics-related concepts to understand numbers, quantities, and shapes in ways that can be integrated into the five focal areas. On the other hand, in the new Course of Study for Kindergarten, an interest in and a sense of numbers, quantities, and shapes are emphasised as one of the expectations of how children should grow at the end of kindergarten education, which was not mentioned explicitly in the previous version. Further, under the Environment Objective, the importance of mathematics is mentioned thus: "Pupils should have an interest in numbers, quantities, and shapes in their daily life" (MEXT 2017b, p. 15). Other than this statement, there is no clear reference to mathematics.

It is in Grade 1 of Japanese primary school, when the children are aged six, that the basic concepts of numbers and numerals begin to be officially and formally dealt with. In primary school mathematics, children are first expected to learn how to count, read, and write numerals up to ten, understand the structure of numbers, and use numerals in reference to concrete and semi-concrete objects. Next, they start learning to compose/decompose numbers up to ten, in preparation for the introduction of addition and subtraction (MEXT 2017a). Children learn multiplication and division for the first time in Grade 2 (age seven-eight). However, some studies (Fuson 1992; Maruyama 2004) suggest that younger children can also manipulate numbers in certain ways, such as "counting on" (Fuson 1992, p. 121), before entering primary school. In Japanese kindergartens, children also informally experience the use of numbers in their daily life; for instance, counting concrete objects, reading numerals, paying money, figuring out which object relates to another given object, and so on. The team included these mathematical concepts in the kindergarten activities in this project.

Compared with primary school mathematics, kindergarten has three peculiar features. First, children learn through playing (Cohrssen et al. 2014; Vogel 2013; Thomas et al. 2011). Second, it is more significant for them to experience mathematical play, and it does not really matter if their answers are correct. Trial-and-error takes primacy at this stage of mathematics education. Finally, kindergarten children deal with concrete material in the ikonic mode and those who are in primary school move to the semiotic mode, where they start using mathematical symbols, per the Structure of Observed Learning Outcome (SOLO) model (Pegg and Tall 2005). This is a structural model of cognitive development that defines a sequence of cognitive levels and cognitive development modes according to the children's ages. This model can help us identify the degree of children's understanding.

In this project, therefore, the team developed activities on the structure of numbers, cardinal and ordinal numbers, and the basic ideas of dividing concrete objects-including the composition and decomposition of numbers. These activities were intended to foster a smooth transition to primary school mathematics. This chapter focuses on dividing concrete objects, related to composition/decomposition. 


\subsection{Values}

The Course of Study for Kindergarten states the importance of values such as collaboration, empathy, and adhering to a moral standard and social norms (MEXT 2017b, pp. 4-5). Its environment and human relationship objectives include the following on values: children should share the various feelings of joy and sadness with the teacher and other children in groups/class and through active interactions with others, think independently and decide to act, convey what they feel and listen to others, and have an interest in and concern for the environment and nature around them (MEXT 2017b, pp. 13-15). These descriptions explain this project's interest in values in mathematical activities for kindergarten.

Research on values in mathematics education (e.g. Kalogeropoulos and Bishop 2017; Seah et al. 2017; Zhang and Seah 2015; Shimada and Baba 2015; Seah et al. 2001) generally proposes three types of values as relevant to mathematical learning: mathematical values, mathematics educational values, and general educational values (Bishop 1996). However, Japanese mathematics educators Shimada and Baba (2015), introduced a different tripartite division: mathematical values, social values, and personal values. They focused on students' social values and their transformation through problem-solving in class at the primary level in Japan and discussed the fundamental question of whether children at the kindergarten level exhibit social values. According to them, mathematical values include rationalism (Bishop 1988), while social values are defined as notions that children present in real-life settings and society in problem-solving (Shimada and Baba 2015). Bishop (1988) and Shimada and Baba (2015) both defined mathematical values in a similar manner. Considering the ultimate objective of kindergarten in Japan, social and personal values and their development are regarded as important for children's general development, with mathematical and mathematics educational values less so. This chapter will adopt Shimada and Baba (2015)'s framework. It will also examine how both social and personal values relate to mathematical values, which are fundamental values that children will carry into mathematics class in primary school. Successfully capturing these three types of values during mathematical activities at the kindergarten stage will provide even more reason to focus on mathematical activities as they foster a variety of values in children while offering fundamental values that children require in order to be good citizens.

Considering the developmental stage of kindergarten-age children, it is likely to be difficult for them to communicate their values through discussion. However, it may be possible for the teacher to create a setting in which they can show or manifest their own social and personal values, which are also connected to their mathematical values. It is worthwhile to examine children's values in mathematical learning contexts because values-related mathematical activity offers an opportunity for children to share their ideas and thinking. In other words, mathematical activities planned with values in mind may integrate two different skills: deepening the basic concepts of numbers and division, and expressing one's opinion based on one's daily life and ideas. Both of these seem essential to learning at the kindergarten level. 


\subsection{Method}

The author developed a mathematical activity called "sweet potato digging" in the framework of this program.

(1) Setting a problem within the activity: Sweet potatoes have long been popular in Japanese agriculture and related to cultural life in Japan since the Edo period (B.C. 1600) (Ito 2010). Children plant and harvest them with teachers' support for educational purposes as a seasonal and special activity. They plant sweet potatoes around May (which can also be an opportunity for other types of learning, such as learning about agriculture). The activity can continue right through to harvesting in October. On the day before the final part of this activity, the children go out into the field and dig up the sweet potatoes. On the following day (the day of the activity), they wash the sweet potatoes in the morning and then engage in an activity about composition/decomposition of numbers using them. After the activity, they eat the sweet potatoes. Thus, the activity is connected to the children's daily life — as both a familiar food and learning tool—and to seasonal events such as planting and harvesting.

(2) Preparation/materials needed: Sweet potatoes, pictures of mice and moles, and rubber bands.

(3) Purpose of the activity:

(i) To find pairs of numbers using sweet potatoes that add up to five or to ten, and to recognise that these numbers always add up to the same number-five or ten, and;

(ii) To observe what kind of values are appearing throughout the activity.

(4) Class/group organisation: Team teaching (one teacher teaches while the other supports the activity when needed) and pair activities. The teacher chose an activity in which students were paired due to time constraints, as well as because the resultant collaboration and verbal communication between pupils are significant for learning.

(5) Implementation of the activity:

(i) To reflect on sweet potato digging on the previous day and to understand the setting of the activity.

(ii) To introduce mice and moles and explain that the children are going to feed them.

(iii) To decompose five: Children in each pair put rubber bands on sweet potatoes and decide how many will be given to mice and moles respectively, placing the rubber bands on the sweet potatoes and putting them into a designated box.

(iv) To explain how and why they decided to distribute the sweet potatoes in such a way.

(v) To make sure the sum of the two numbers is five. 
(vi) To decompose ten: Representative pairs, who are randomly chosen by the teacher, place rubber bands on sweet potatoes and decide how many sweet potatoes are going to mice and moles respectively and put them into the designated box.

(vii) To explain how and why they decided to distribute the sweet potatoes in such a way.

(viii) To make sure the sum of the two numbers is ten.

(ix) To reflect upon the activity.

\subsection{Results}

The activity was conducted in a public kindergarten in Tokyo in October 2015. After the research was permitted by the university, the author was given permission to take photos of children by the school principal and class teacher. The author recorded the activity for data collection and took fieldnotes of the different group activities as each group was working at the same time. The activity consisted of three separate trials. Two teachers, the class teacher and head teacher who implemented this activity, prepared four desks at which the pairs worked; the rest of the children awaited their turn, sitting on the chair and listening to the presentations after each trial.

After the activity, the DVD data were transcribed and analysed qualitatively. The number of participating children was sixteen, aged five to six. In class, the teacher created a backstory to help the children understand the activity and imagine a context for it. She told them about an imaginary restaurant that served sweet potatoes to moles and mice, and asked the children to decide how many to serve to these "customers", supposing that the two groups of animals could eat five altogether. She also asked them if they could find novel ways to divide the sweet potatoes-one for the moles and four for the mice, for example; or maybe three for the moles and two for the mice.

Following this explanation by the teacher, every child understood what they were supposed to do. Then, a mathematically bright child asked:

1 S1: Can we divide one sweet potato in half, because we want to divide them equally to both mice and moles? I would feel very sorry for the mice, if mice were given two, and moles were given three.

To which the teacher replied:

$2 \mathrm{~T}$ : Because we do not have any knives to cut, we cannot halve one sweet potato, can we? But I understand that you want to split them equally, right? If moles were given more, the next pair might give more sweet potatoes to mice than the first group.

This child's question shows that he thought it was important to divide things equally. After the conversation, eight pairs of students completed the activity, dividing the sweet potatoes among the mice and the moles in various ways across the three trials. Table 11.1 shows the results of the activity, including conversations and actions. 
Table 11.1 How each pair divided the sweet potatoes and why

\begin{tabular}{|c|c|c|c|}
\hline \multirow[t]{2}{*}{$\begin{array}{l}\text { Pair } \\
\text { no. }\end{array}$} & \multicolumn{2}{|c|}{$\begin{array}{l}\text { No. of sweet } \\
\text { potatoes }\end{array}$} & \multirow[t]{2}{*}{$\begin{array}{l}\text { Reasons, talk, or actions for dividing in this way, according to } \\
\text { children }\end{array}$} \\
\hline & Mice & Moles & \\
\hline 1 & 3 & 2 & "Because mice are smaller than moles, we feel sorry for the mice" \\
\hline 2 & 2 & 3 & (No response) \\
\hline 3 & 1 & 4 & $\begin{array}{l}\text { "Because this (a sweet potato for the mice) is too big compared to } \\
\text { these ones for moles" }\end{array}$ \\
\hline 4 & 2 & 3 & "Because we feel sorry for the small mice" \\
\hline 5 & 3 & 2 & $\begin{array}{l}\text { (Child A) "Because the mice are smaller" } \\
\text { (Child B) "Because the mouths of moles are very big, and the } \\
\text { mouths of mice are small" }\end{array}$ \\
\hline 6 & 3 & 2 & $\begin{array}{l}\text { (Teacher) "You gave the bigger size of sweet potatoes to moles, and } \\
\text { the smaller size to mice?" (Children) "Yes." (The children were not } \\
\text { able to express the reason although the teacher asked them.) }\end{array}$ \\
\hline 7 & 5 & 0 & $\begin{array}{l}\text { (The teacher told the other children instead of this pair.) "They } \\
\text { thought they wanted to try a way of dividing which had never } \\
\text { happened so far, right?" (The pair nodded. They could not express } \\
\text { their reason but agreed with the teacher by nodding.) }\end{array}$ \\
\hline 8 & 4 & 1 & "We gave more to the mice because they were hungry" \\
\hline
\end{tabular}

Table 11.1 shows that the most common way that these children choose of dividing five sweet potatoes was into two and three. There were a few groups such as pairs 6 and 7, which were not able to say anything, and the teacher helped them out, so they ended up agreeing with her. It also reflects the children's own logical thinking as expressed by them verbally: the reasons for the division and distribution were related to the size of the animals and their mouths. For instance, pair 6 distributed three sweet potatoes to mice and two sweet potatoes to moles, but carefully chose the bigger sweet potatoes for the moles. Two pairs 3 and 8 , chose to divide the sweet potatoes into one and four, with a focus on the size of the animals. The seventh pair, which decided to divide them five/zero, was strongly criticised by the other children as shown in the excerpts from the class. This conversation was as follows:

$1 \mathrm{~T}$ : Well, next (pair 7 in Table 11.1), let's have a look. Wow, this is new. They want to create a new approach. They seem to have given only mice sweet potatoes. Can you count how many you have given to the mice, together?

2 S1: One, two, three, four, five.

3 T: I see, I mean, how many were given to the moles?

$4 \mathrm{~S} 2$ : Zero.

$5 \mathrm{~T}$ : Wow, zero. Mice are given five and moles are given zero. How many sweet potatoes do they have altogether?

6 S1: Five (Showing five using their fingers too).

$7 \mathrm{~T}$ : Wow, moles were not given any sweet potatoes to eat, even when we have found five sweet potatoes. 
$8 \mathrm{~S} 3$ : The moles are so sorry.

9 S4: They are pitiable. (Noise from some children: "Pitiable, pitiable!")

10 S5: I feel pity.

$11 \mathrm{~T}$ : Well, I would guess that they might think they want to create something new that nobody has served before in the restaurant. Okay? And thank you very much to the seventh group.

As the transcript shows, while the teacher was interested in and respectful of the seventh pair's mathematically novel approach, the other children were not happy at all and were generally more attentive to fairness than to new mathematical findings. Pair 7 kept quiet, but it seemed that they felt relieved by the teacher's support as everyone in class was complaining about their result.

After the pair activity, the class proceeded to the next task, which involved ten sweet potatoes. The teachers combined the two restaurants that had been running simultaneously up to that point into a bigger one, saying, "Very hungry moles and mice! We are now in a bigger restaurant." The children then counted the number of sweet potatoes, which was now ten. Two pairs of children came to the front and demonstrated how they would divide ten sweet potatoes. One pair distributed three to the mice and seven to the moles, while the other distributed four to the mice and six to the moles, as shown in the excerpts from the class interaction below:

$1 \mathrm{~T}$ : The first and second group showed different results. They are different, aren't they? In the first pair, the moles can eat seven sweet potatoes. On the other hand, in the second pair, the moles can eat only six. This means...

2 S5: Six is less than seven by one.

$3 \mathrm{~T}$ : Oh, yes. In the second pair, the moles are given six and the mice are given four, and then we find ten sweet potatoes. Hm? In the first pair, seven sweet potatoes are distributed to moles, three to mice. In the second pair, four to mice and six to moles, but the total number of sweet potatoes is...

4 Most children: Ten.

5 S7: Yeah, ten. (Instantly answering after 4)

$6 \mathrm{~T}$ : I thought it would not be like that, but we found ten.

7 S8: And if we add, they will become twenty.

\subsection{Discussion}

\subsubsection{Cognitive Outcome: Children's Activities of Dividing Two Quantities from a Logical Perspective}

Working in pairs, all the children succeeded in dividing the sweet potatoes. While they were separating them or explaining their chosen distribution, they counted the objects by using their fingers and saying the numbers simultaneously. All of them were able to count up to five in this way. Then, two representative pairs succeeded in 
decomposing ten. Unfortunately, other pairs did not complete that part of the activity due to limited time, although they showed an interest in trying it. When counting numbers, everyone counted out loud. At the end of the activity, one child noted that ten plus ten is twenty, which was an advanced observation. Others were also counting from ten to twenty.

In the activity, children used concrete objects to help them with decomposing quantities, which might have been part of why they succeeded in dividing ten, and not only five. In the planning phase, the teachers were dubious about whether to introduce ten, because they felt that some children would not be able to handle the bigger quantities. Given the actual results, from a mathematical education point of view, it would be valuable to attempt this activity again to check if all students can work well with ten if given more time.

The teachers verbally confirmed the children's choices and the reasons for them, but emphasis was not placed on this aspect of the activity, and it may be that the children's thinking was not accurately reflected in some cases, such as with the group who split the sweet potatoes into five and zero and kept quiet. This case was not the precise decomposition the author expected, but the fundamental idea of addition was shown. This way of dividing did not make sense to the other children, but it is meaningful as addition. It can be conjectured that the pair 7 children operated solely in the mathematical context of numbers.

As shown in the case of ten in the above transcript, only a few children who seemed to understand the concept of bigger numbers such as ten and twenty participated or responded to the teacher's questions. Another finding was that some children understood the concept of half and double, as shown in the conversations of Sl and teacher for the first, and the last conversation of S8 in the vignettes in the previous section. Thus, various children showed a range of mathematical-cognitive ability, but all had a solid minimum threshold of understanding toward the number five, when using concrete objects.

\subsubsection{Children's Social and Personal Values Shown Through the Activity}

Although the children's values were not always clearly distinguished, with a few exceptions, the qualitative data above hints at two characteristics of these children's personal and social values. First, the children regarded equality as very important. That is, they appeared to value equality in that most pairs tried to give equal amounts to the different animals and had compensating reasons why one animal received more than the other. Historically speaking, during the Edo Era (1600-1867), the Japanese people shared the view of equality as an important philosophy even before the Meiji Restoration (around 1867). The philosophy, on the other hand, was somewhat different from what Western countries regarded as equality, according to Suzuki (2009). Earlier in Japan, equality was based on the philosophical ideas of Buddhism, 
while the idea of equality in Europe is embedded in Christianity. Moreover, a few philosophers, who studied in different countries in Europe, imported various ideas of equality. This actually accelerated the difference in its interpretation. In the current school education system, equality between boys and girls, as well as co-operation and sharing with friends in an equal manner, are emphasised, which Cummings (2014) also stated with regards to the Japanese primary school. Moreover, both the government and society believe that achieving equality is a fundamental and significant goal-especially between men and women, as well as between those with a disability and the able-bodied (e.g. MEXT homepage 1992; Gender Equality Bureau Cabinet homepage 2018). A similar view of what society regards as important was also observed during the activity in the kindergarten.

At the beginning of the class, a boy (S1) wanted to cut one sweet potato in half, a suggestion that seemed advanced for the kindergarten level. Here, the boy showed the personal values of equality connected to mathematical values in that he presumably believed that having equal amounts is the same as the philosophical notion of equality. However, this may not always be the case, as in societal values, other aspects of the context may override the notion of equal amounts.

Table 11.1 also supports the importance of equality among children. For example, pair 3 considered the 'size' of the sweet potatoes allocated to the moles and mice, to make the actual quantities more equal, rather than the 'numbers' of sweet potatoes equal. This also reflects the social and personal values of equality. Second, the teacher wanted children to find new ways of dividing the sweet potatoes, but the children thought that fairness was very important and preferred to focus on that instead of novelty. Giving all five sweet potatoes to only one group of animals by pair 7 was not accepted by the majority of children, even though it was a new approach as the teacher suggested; the children could not understand how such division would be fair. This implies that the children were strongly engaged in the context created by the teacher, and that the social values evoked by the mice and moles were much greater than the mathematical novelty that the teacher encouraged, which will be emphasised in the children's primary school mathematics lessons. The children's valuing of the importance of equality has come from their daily life situations, where, for instance, they divided food equally with friends and siblings, which the teachers reported to us after the activity.

This also reflects the values adults convey to children in Japanese kindergarten and society and could easily lead into activity and concept acquisition related to addition, subtraction, and division in the future. The children's strong sense of fairness may be possible to harness as a driving force to help them learn how to divide equally in mathematical terms in the future. The author intends to plan and implement such an activity at the kindergarten level. 


\subsubsection{From Social and Personal Values Toward Mathematical Values}

First, the boy who asked if he could halve the sweet potato, as well as pair 7 demonstrated the mathematical value of rationalism, according to the definitions of mathematical values. The first boy wanted to divide the potato equally, which is a basic fractional way of thinking, and clearly connected to mathematical values. Further, the seventh pair provided a different, novel mathematical possibility for the division of the sweet potatoes. This was partially because the teacher encouraged the children to find new ways, and they acted on this suggestion. Although the other children disagreed with the pair, their disagreement was on non-mathematical grounds. The seventh pair's action and thought are primarily based on their mathematical values. In primary school, learning often happens in daily life situations when children think mathematically. This action is connected to the beginning of these ways of mathematical thinking. Second, the relationships some students focused on were firstly the number of sweet potatoes respectively given to mice and moles, and secondly the size of the animals and their mouths. They engaged with the imaginary setting and balanced multiple variables - different relationships of different quantities and sizes - in a fairly sophisticated way, which is the very first stage of mathematical functions. Based on their verbal responses, dealing with many variables in this way can be seen to have helped elicit the start of rationalism in mathematics for them, even though their ways were primitive and sometimes needed to be assisted by the teacher. That is, the social and personal values they showed — in brief, fairness-were the driving force for them to think and express themselves logically, which was then related to the development of important elements of their mathematical values, which can be rationalism.

\subsection{Conclusion}

The focus on children's social and personal values in the activity helped demonstrate that they met the developmental requirements for the educational stage and to some extent, rationalism (one of the mathematical values) appeared in some scenes. At the kindergarten level, it is significant to grow their personal and social values but at the same time, this case study showed there is a possibility to foster their mathematical values. If kindergarten activities, including activities for primary education such as in the case study, contain aspects of the three given values, they will be effective both for holistic development and mathematical development in the children's lives.

Acknowledgements I would like to show my appreciation to the teachers and principal of the kindergarten where this study was conducted. The research was funded by Japan Society for the Promotion of Science research grant no. 15H02911. I also would like to thank Editage (www.editage.jp) for English-language editing. 


\section{References}

Bishop, A. (1988). Mathematical enculturation: A cultural perspective on mathematics education. Dordrecht: Kluwer Academic Publishers.

Bishop, A. (1996). How should mathematics teaching in modern societies relate to cultural values-Some preliminary questions. Paper Presented at the Seventh Southeast Asian Conference on Mathematics Education, Hanoi, Vietnam.

Cohrssen, C., Church, A., \& Tayler, C. (2014). Pausing for learning: Responsive engagement in mathematics activities in early childhood settings. Australasian Journal of Early Childhood, 39(4), 95-102.

Cummings, K. W. (2014). Education and equality in Japan. Princeton: Princeton University Press.

Fuson, K. C. (1992). Research on learning and teaching addition and subtraction of whole numbers. In G. Leinhardt, R. T. Putnam, \& R. Hattrup (Eds.), Analysis of arithmetic for mathematics teaching (pp. 53-187). Hillsdale, NJ: Lawrence Erlbaum.

Gender Equality Bureau Cabinet homepage. (2018). What is a gender-equal society? http://www. gender.go.jp/about_danjo/society/index.html.

Ito, S. (2010). Sweet potato and Japanese. Tokyo: PHP New Books.

Kalogeropoulos, P., \& Bishop, J. A. (2017). What is the role of value alignment in engaging mathematics learners? Paper Presented at the 9th Mathematics, Education and Society Conference, Volos, Greece.

Maruyama, R. (2004). Children's strategies of addition and subtraction tasks of sets. Bulletin of Joetsu University of Education, 24(1), 257-270.

Matsuo, N. (2015). Shaping pre-school mathematics education program: Focusing on the activity of comparing area. In Proceedings of 48th Autumn Research Forum (pp. 31-34). Shinshu, Japan: Japan Society of Mathematical Education.

Ministry of Education, Culture, Sports, Science, and Technology, Japan (MEXT). (1992). Survey for equality of men and women. Retrieved March 22, 2018, from http://www.mext.go.jp/b_menu/ hakusho/nc/t19921101001/t19921101001.html.

MEXT. (2008). The kindergarten course of study. Tokyo: MEXT.

MEXT. (2017a). The elementary school course of study. Tokyo: MEXT. http://www.mext.go.jp/ component/a_menu/education/micro_detail/_icsFiles/afieldfile/2017/05/12/1384661_4_2.pdf.

MEXT. (2017b). The course of study for kindergarten. Tokyo: MEXT. http://www.mext.go.jp/ component/a_menu/education/micro_detail/_icsFiles/afieldfile/2017/05/12/1384661_3_2.pdf.

Pegg, J., \& Tall, D. (2005). The fundamental cycle of concept construction underlying various theoretical frameworks. ZDM Mathematics Education, 37(6), 468-475.

Seah, W. T., Bishop, A. J., FitzSimons, G. E., \& Clarkson, P. C. (2001). Exploring issues of control over values teaching in the mathematics classroom. Paper Presented at Annual Conference of the AARE, Fremantle. http://citeseerx.ist.psu.edu/viewdoc/download?doi=10.1.1.499.1752\& rep=rep1\&type $=$ pdf.

Seah, W. T., Davis, K. E., \& Carr, E. M. (2017). School mathematics education through the eyes of students in Ghana: Extrinsic and intrinsic valuing. Paper Presented at CERME10, Dublin, Ireland. Retrieved from https://www.researchgate.net/publication/312452221/download.

Shimada, I., \& Baba, T. (2015). Transformation of students' values in the process of solving socially open-ended problems. In K. Beswick, T. Muir, \& J. Wells (Eds.), Proceedings of 39th Psychology of Mathematics Education Conference (Vol. 4, pp. 161-168). Hobart, Australia: PME.

Suzuki, S. (2009). Freedom and equality in Meiji Japan. Japan Research, 40, 377-391.

Thomas, L., Warren, E., \& de Vries, E. (2011). Play-based learning and intentional teaching in early childhood contexts. Australasian Journal of Early Childhood, 36(4), 69-75. 
Vogel, R. (2013). Mathematical situations of play and exploration. Educational Studies in Mathematics, 84, 209-225.

Zhang, Q., \& Seah, W. T. (2015). Chinese secondary teachers' and students' perspectives of effective mathematics teaching: The underlying values. In K. Beswick, T. Muir, \& J. Wells (Eds.). Proceedings of 39th Psychology of Mathematics Education Conference (Vol. 4, pp. 337-344). Hobart: PME.

Open Access This chapter is licensed under the terms of the Creative Commons Attribution 4.0 International License (http://creativecommons.org/licenses/by/4.0/), which permits use, sharing, adaptation, distribution and reproduction in any medium or format, as long as you give appropriate credit to the original author(s) and the source, provide a link to the Creative Commons license and indicate if changes were made.

The images or other third party material in this chapter are included in the chapter's Creative Commons license, unless indicated otherwise in a credit line to the material. If material is not included in the chapter's Creative Commons license and your intended use is not permitted by statutory regulation or exceeds the permitted use, you will need to obtain permission directly from the copyright holder.

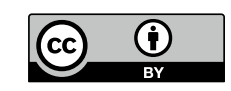

